\title{
APLIKASI METODE GEOLISTRIK TAHANAN JENIS UNTUK MENGETAHUI BAWAH PERMUKAAN DI KOMPLEK CANDI BELAHAN (CANDI GAPURA)
}

\author{
Juan Pandu Gya Nur Rochman, Amien Widodo, Ayi Syaeful Bahri, Firman Syaifuddin, Wien Lestari \\ Teknik Geofisika, Fakultas Teknik Sipil dan Perencanaan, Institut Teknologi Sepuluh Nopember \\ djuan.rochman@gmail.com
}

\begin{abstract}
Abstrak. Gunung Penanggungan merupakan gunung yang memiliki sejarah yang tinggi di Jawa Timur. Hal ini dibuktikan dengan banyaknya candi yang mengelilingi di komplek gunung ini. Setidaknya terdapat 116 yang ditemukan. Komplek Situs belahan merupakan salah satu komplek bangunan candi yang besar. Candi Gapura merupakan bagian pintu masuk dari komplek bangunan ini yang sebagian bangunannya masih terpendam. Tujuan penelitian ini adalah untuk mengetahui kondisi bawah permukaan di komplek candi tersebut. Metode yang digunakan dalam penelitian ini adalah Metode Geolistrik Tahanan jenis. Prinsip metode ini adalah menginjeksikan arus listrik ke permukaan tanah melalui sepasang elektroda dan mengukur beda potensial dengan sepasang elektroda yang lain. Metoda ini memanfaatkan sifat kelistrikan suatu material untuk mengetahui karakteristik dari suatu material. Jumlah lintasan yang digunakan sebanyak 8 lintasan yang terletak di Candi Gapura A (4 lintasan) dan Candi Gapura B (4 lintasan). Dari pengkuran geolistrik didapatkan profiling resistivitas bawah permukaan tanah yang dapat mengetahui dugaan sebaran bangunan candi. Hasil intepretasi 8 lintasan secara umum dibagi dua lapisan. Pada kedalaman 0-4 meter nilai resitivitasnya 1-6 ohm meter diintepretaskan sebagai lapisan lempung. Pada lapisan ini juga terdapa nilai resitivitas 10-20 ohm meter diduga runtuhan batu bata candi. Pada lapisan kedua dengan kedalaman lebih dar 4 meter dengan nilai resistivitas 100-150 ohm meter diduga lapisan kerkil (zona keras). Pada Batas lapisan ini (kedalaman 4 meter) diduga terdapat altar atau pelataran karena pada semua lintasan terdapat kontras nilai resitivitas tinggi dan rendah pada kedalaman yang hampir sama untuk tiap lintasan pengukuran.
\end{abstract}

Kata kunci : metode geolistrik; Situs belahan; Candi Gapura; Penanggungan

\begin{abstract}
Penanggungan Mountain is a mountain with a deep history located in East Java. A lot of temples around this mountain become a strong evidence of the history. Until now, there are at least 116 temples has been found. Situs Belahan cluster is one of large temple cluster. Gapura temple is an entry point of this cluster which some part still buried underground. Hence this research aims to determine the subsurface condition of that cluster. The method used is Geoelectric Resistivity method. This method performed by giving injection of electric current to the ground through a pair of electrodes and also measuring the potential difference through another pair of electrodes. This method uses the electrical properties of a material to determine the characteristics of a material. Number of line used is 8 lines which are located on Temple Gate A (4 lines) and Temple Gate B (4 lines). By this geoelectric measurement, it can determine the profiling of underground resistivity which could be used to detect the distribution of temples location. Interpretation result of 8 lines generally consists of two layers. At a depth of $0-4$ meters, the resistivity value shows around 1 - 6 ohm meter.which is interpreted as layer of clay.. In this layer there is also resitivity value around $100-150$ ohm meter which is interpreted as brick of temple's ruins. In the second layer with a depth of over 4 meters shows resistivity value of 100-150 ohm meter, which suspected as gravel layer (hard zone). At this limit (depth of 4 meters), it is suspected that there is altar or prayer yard because all lines shows a contrast of high and low resitivity value at the almost same depth that is almost the same for each line.
\end{abstract}

Keywords: Geolectrical Method; Belahan site; Gapura Tamples; Penanggungan.

\section{PENDAHULUAN}

Jawa Timur memiliki banyak peninggalan bersejarah. Salah satunya adalah komplek situ Gunung Penanggungan. Gunung ini merupakan gunung berapi yang sedang tidur atau sedang dalam keadaan tidak aktif karena tidak ada catatan letusan 1000 tahun yang lalu (Van Padang, 1951). Namun yang menarik adalah bentukan kerucut seperti gunung yang aktif. Gunung yang memiliki ketinggian 1653 M dari atas permukaan laut ini terletak di 
kabupaten Mojokerto dan Kabupaten Pasuruan. Gunung ini memiliki nilai sejarah tinggi karena di bagian lerengnya banyak ditemukan berbagai peninggalan purbakala, berupa candi, pertapaan, maupun petirtaan dari periode Hindu-Budha di Jawa Timur. Setidaknya terdapat 116 yang ditemukan di komplek ini penanggungan ini (Sidomulyo $H, 2013$ )

Salah satu bagian yang menarik dari komplek situs Gunung penanggungan adalah Situs Belahan. Sejumlah benda purbakala ditemukan di sini misalnya gapura, candi, dan kolam pemandian. Karena aeranya cukup luas. Dari hasil penelitian yang pernah dilakukan, diketahui bahwa situs belahan ini merupakan komplek yang besar yang dikelilingi tembok (Resink, 1968).

Metode yang digunakan untuk mengetahui bawa permukaan adalam metode geofisika. Salah satu metoda geofisika yang biasa digunakan untuk mengatahui bawah permukaan tanah dan sebaran candi adalah metoda resistivitas (Griffiths and Barker, 1994; Arwananda dkk., 2016). Metoda ini memanfaatkan sifat kelistrikan suatu material untuk mengetahui karakteristik dari suatu material. Metode ini terbukti mampu secara efektif untuk mengetahui bangunan arkeologi karena dapat membedakan nilai resistivitas yang mencolok antara bangunan yang berongga dan batuan yang disekitarnya (Abbas et al., 2016).

\section{KONDISI GEOLOGI}

Berdasarkan peta geologi lembar Malang (Santosa and Suwarti, 1992), daerah Gunung Penanggungan tersusun atas satu formasi yaitu: Formasi Qvn (Batuan gunungapi kuarter atas). Formasi ini tersusun atas breksi gunungapi, lava, tuf, breksi tufan, aglomerat dan lahar hasil erupsi Gunung Penanggungan. Di bawah Formasi Qvn terdapat beberapa formasi batuan seperti Tuf Rabano (Qvtr), Batuan Gunungapi Tengger (Qvt), dan Batuan Gunungapi Arjuno-Welirang (Qvaw). Sedangkan formasi yang lebih muda dari formasi Qvn diantaranya; endapan rombakan cemara tiga (Qtt), batuan Gunungapi Bromo (Qvb), pasir Gunungapi Tengger (Qvs), endapan teras ( $Q t)$, dan aluvium (Qa). Pada lokasi pengukuran lapisan yang terlihat adalah aluvium. AlluviumTersusun atas kerakal, kerikil, pasir, lempung, lumpur.

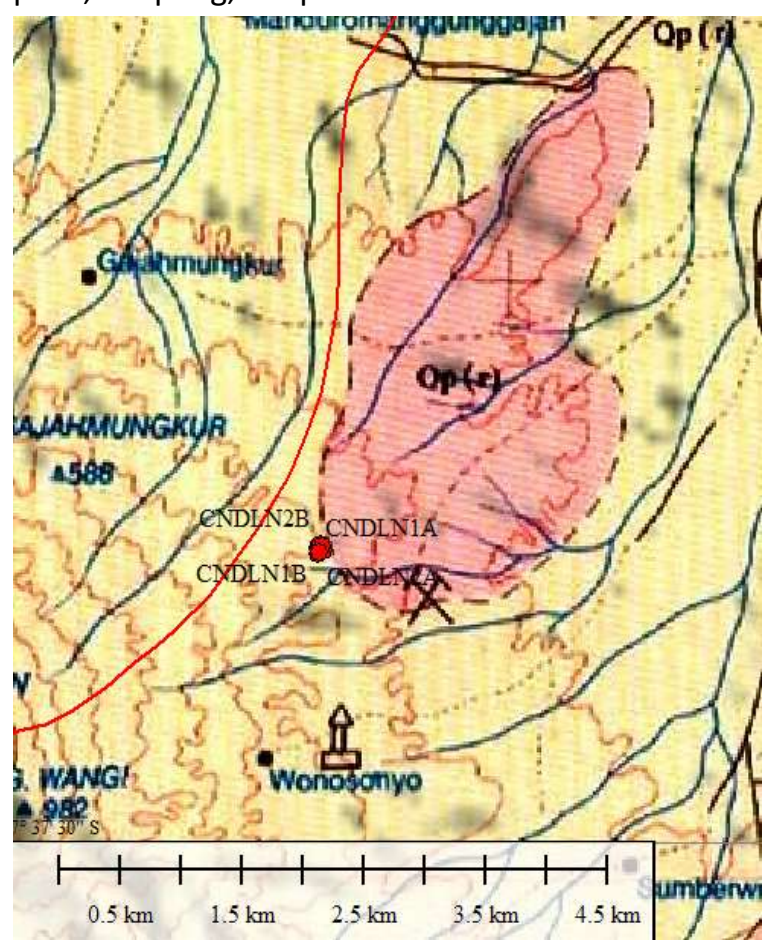

Gambar 1 Peta Geologi Sekitar Candi Belahan (Santosa dan Suwarti, 1992)

\section{METODE GEOLISTRIK TAHANAN JENIS}

Metode geolistrik merupakan metode yang digunakan untuk mempelajari sifat aliran listrik di dalam bumi dengan cara mendeteksinya di permukaan bumi (Lilik Hendrajaya,1990). Prinsip kerja metode geolistrik dilakukan dengan cara menginjeksikan arus listrik ke permukaan tanah melalui sepasang elektroda dan mengukur beda potensial dengan sepasang elektroda yang lain. Hasil pengukuran arus dan beda potensial untuk setiap jarak elektroda tertentu, dapat ditentukan variasi harga hambatan jenis masing-masing lapisan di bawah titik ukur.

Harga resistivitas yang didapatkan merupakan resistivitas semu. Persamaan resistivitas semu $\left(\rho_{a}\right)$ sebagai berikut

$$
\rho_{a}=K \frac{\Delta V}{I}
$$

$\mathrm{V}=$ beda potensial $(\mathrm{mV})$ 
$\mathrm{I}=\operatorname{arus}(\mathrm{mA})$

dengan

$K=\frac{2 \pi}{\left[\left(\frac{1}{r_{1}}-\frac{1}{r_{2}}\right)-\left(\frac{1}{r_{3}}-\frac{1}{r_{4}}\right)\right]}$

Dimana $\mathrm{K}$ adalah faktor geometri yang merupakan besaran koreksi letak kedua elektroda potensial terhadap elektroda arus(Reynolds, 1997).

Konfigurasi yang digunakan adalah konfigurasi wenner yaitu jarak antara elektroda arus dan elektroda potensial sama (Gambar 2). Sehingga faktor konfigurasinya adalah sebagai berikut :

$K=2 \pi a$

(3)

Dimana a merupakan spasi elektroda.

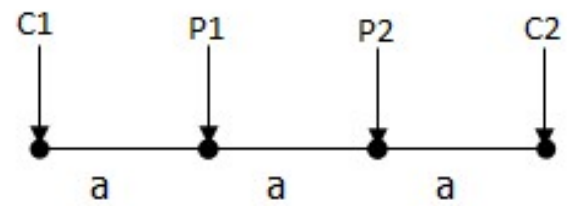

Gambar 2 Skema konfigurasi Wenner

\section{METODOLOGI}

Lokasi Penelitian ini berada di komplek candi belahan yang terletak di Desa Wonosunyo, Kecamatan Gempol, Pasuruan, Jawa Timur. Lokasi dapat di lihat pada Gambar 3

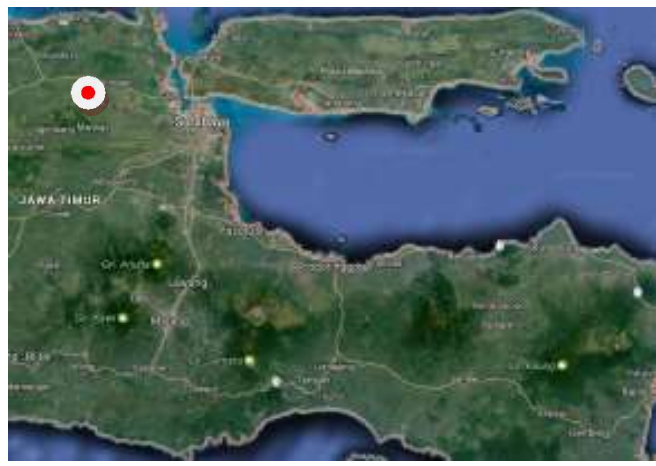

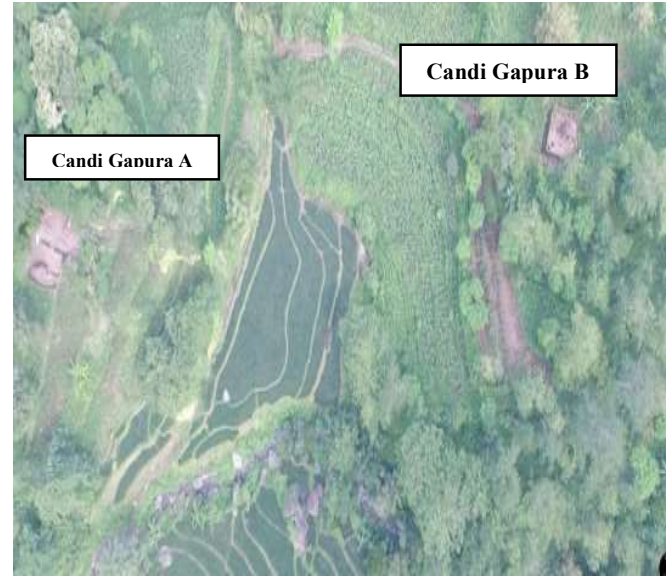

Gambar 3 Lokasi Candi Belahan

Pengukuran geolistrik dilakukan pada tanggal 13 - 14 Agustus 2016. Alat yang digunakan pada penelitian ini adalah geolistrik Georest multhichannel. Jumlah lintasan pengukuran sebanyak 8 lintasan. 4 lintasan di Candi Gapura A dan 4 lintasan di Candi Gapura B (Gambar 4 dan Gambar 5)

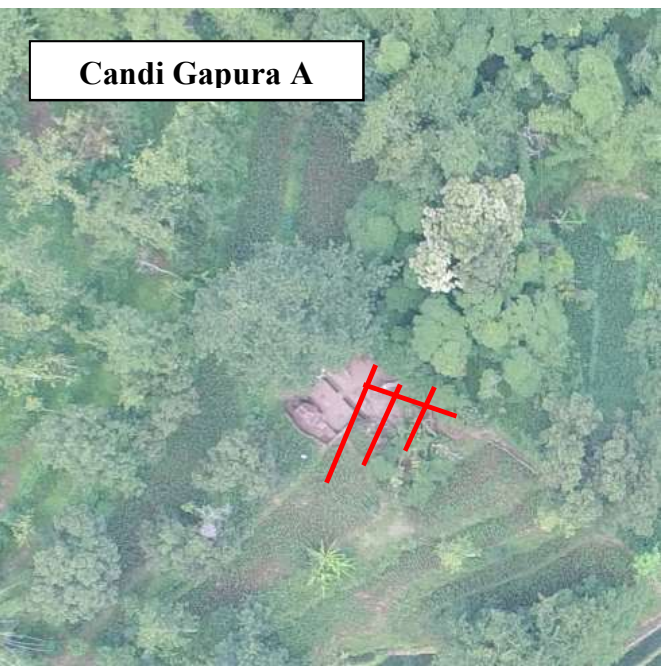

Gambar 4 Lintasan Geolistrik pada Candi Gapura A 


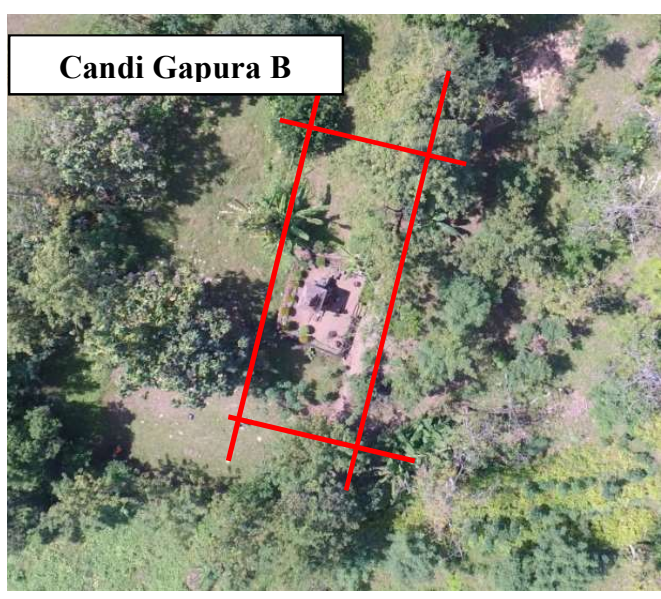

Gambar 5 Lintasan Geolistrik ada Candi Gapura B

Konfigurasi yang digunakan adalah wenner dengan spasi antar elektroda 1-3 $\mathrm{m}$ dengan panjang lintasan 100-155 m. Data yang di dapatkan dari pengukuran geolistrik adalah nilai hambatan (R). Nilai Resistivitas semu didapatkan dengan mengalikan faktor geometri. Pengolahan data geolistrik dilakukan dengan menggunakan Res2divn. Hasil dari pengolahan data geolistrik resistivitas 2D didapatkan variasi tahanan jenis dan ketebalan lapisan untuk tiap lintasan. Dari penampang 2D tersebut di buat penempang 3D untuk memudahkan intepretasi.

\section{HASIL DAN PEMBAHASAN}

Pengukuran Geolistrik di 8 titik pengukuran kemudian dilakukan pengolahan data dengan RES2DINV. Hasil dari pengolahan ini berupa penampang 2D masing - masing lintasan. Berikut hasil contoh pengolahan data geolistrik pada lintasan 1 candi Gapura A Gambar 6 dan Gambar 7.

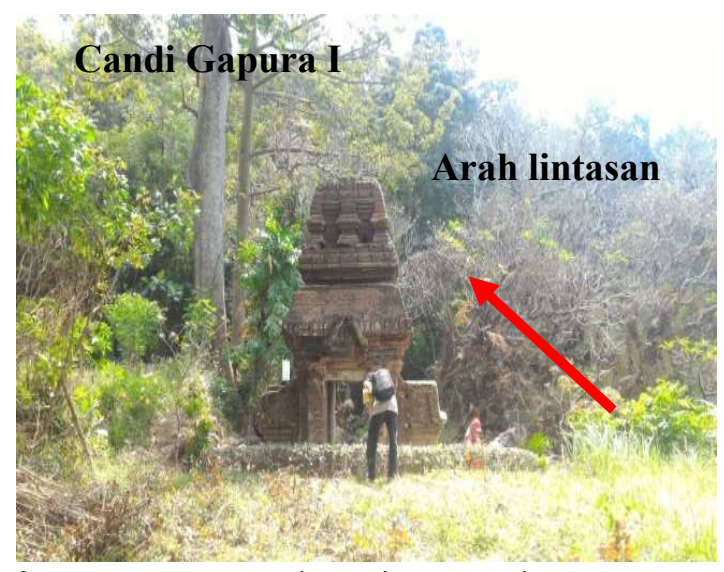

Gambar 6 Lintasan pengukuran line 1 Candi Gapura A

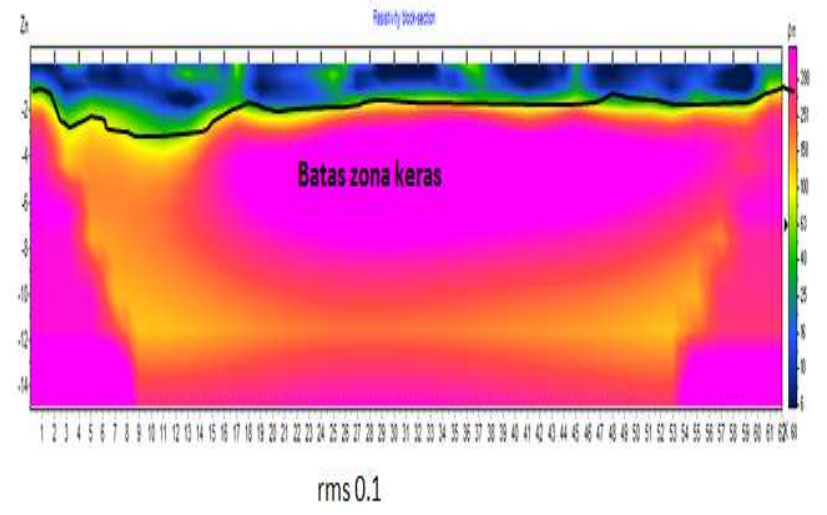

Gambar 7 Penampang resitivitas 2D hasil inversi lintasan 1 Candi Gapura A

Pada Gambar 8merupakan hasil penggabungan 4 titik pengukuran di candi Gapura 1. Penggabungan lintasan tersebut menjadi 3D agar memudahkan intepretasi. Secara umum terdapat 2 lapisan utama lapisan dengan kedalam 0-4 meter ini merupakan lapisan top soil (lempung) pada lapisan lempung ini diduga terdapat batu bata candi. Pada lapisan kedua $>4$ meter terdapat lapisan yang lebih keras (kerikil) dari ke empat lintasan kedalamannya konstan, ini diduga batas lapisan plataran di sekitar candi.

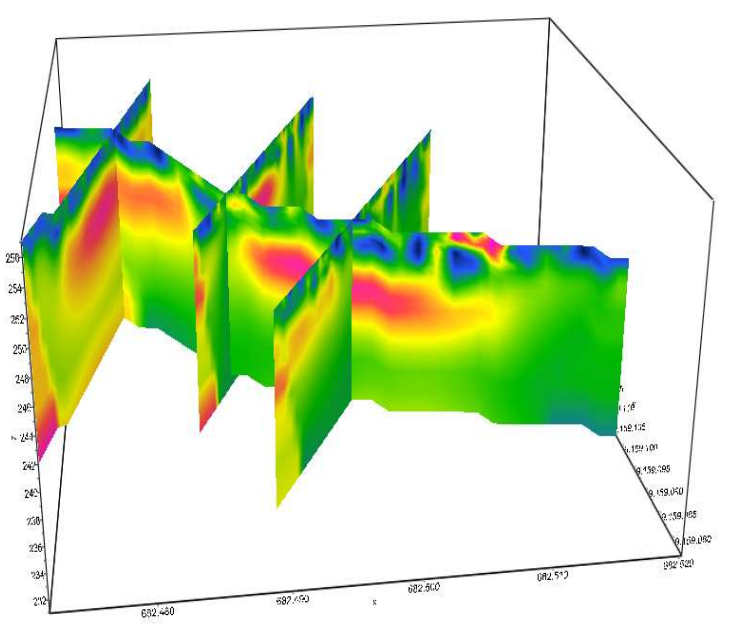

Gambar 8 Penampang 3D Candi Gapura A

Hasil pengukuran geolistrik di candi Gapura 2 dilakukan penggabungan 4 lintasan menjadi 3D (Gambar 9). Hasil intepretai candi gapura 2 ini mirip dengan candi gapura 1 . Terdapat dua lapisan utama yang pertama lapisan lempung dengan kedalaman 0-4 meter dan lapisan kerikil (lapisan lebih keras) 
pada kedalaman $>4$ meter. Pada kedalaman 4 meter ini diduga merupakan altar atau pelataran di sekitar candi Gapura 2.

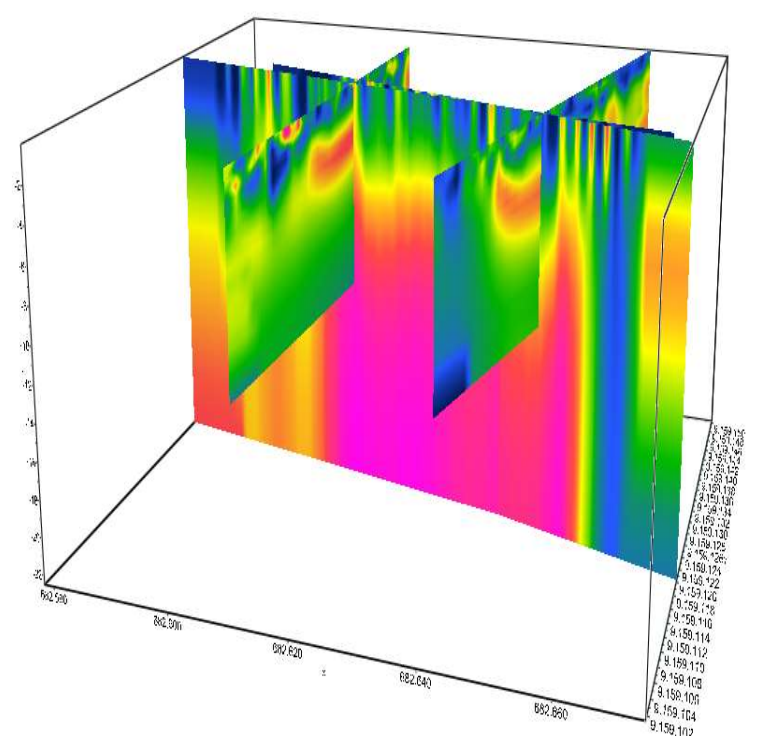

Gambar 9 Penampang 3D Candi Gapura B

\section{PENUTUP}

\section{Simpulan}

Kesimpulan yang dapat ditarik pada penelitian ini adalah sebagai berikut :

1. Hasil Pengukuran Geolistrik Candi Gapura I dan Gapura II pada kedelapan lintasan pada kedalaman 0-4 meter nilai resistivitasnya nilai resitivitasnya 1-6 ohm meter diintepretaskan sebagai lapisan lempung. Pada lapisan ini juga terdapa nilai resitivitas 10-20 ohm meter diduga runtuhan batu bata candi. Pada lapisan kedua dengan kedalaman lebih dar 4 meter dengan nilai resistivitas 100-150 ohm meter diduga lapisan kerkil (zona keras)

2. Pada Batas lapisan ini (kedalaman 4 meter) diduga terdapat altar atau pelataran karena pada semua lintasan batas nilai resitivitas tinggi dan rendah terdapat pada lapisan yang hampir sama.

\section{Saran}

Saran yang disulkan pada penelitian ini diperlukan pembanding metoda geofisika lainnya misalnya metode Very low Frequency (VLF-EM) dan Ground Penetrating Radar (GPR) supaya dapat dintepretasi lebih detail. Untuk membuktikan lebih detail dari pengukuran geolistrik ini perlu dilakukan bor dangkal kedalam sampai 4 meter untuk memastikan terdapat runtuhan candi dan pelataran di deaerah tersebut.

\section{UCAPAN TERIMA KASIH}

Terima kasih disampaikan kepada ITS atas Hibah Penelitian Pemula Tahun 2016. Peneliti juga berterima kasih kepada Dinas Kebudayaan dan Pariwisata Jawa Timur atas perijinan untuk Akuisisi Data.

\section{DAFTAR PUSTAKA}

Abbas, A.M., Ghazala, H.H., Mesbah, H.S., Atya, M.A., Radwan, A., Hamed, D.E., 2016. Implementation of ground penetrating radar and electrical resistivity tomography for inspecting the Greco-Roman Necropolis at Kilo 6 of the Golden Mummies Valley, Bahariya Oasis, Egypt. NRIAG J. Astron. Geophys. doi:10.1016/j.nrjag.2016.01.003

Arwananda, A.P., Lestari, W., Rochman, J.P., Husein, A., 2016. Efek Patahan Watukosek Pada Geomorfologi Kali Porong dengan Metode Tahanan Jenis 2-D. J. Geosaintek 2, 151-156.

Griffiths, D.H., Barker, R.D., 1994. Electrical Imaging in Archaeology. J. Archaeol. Sci. 21, 153-158. doi:10.1006/jasc.1994.1017

Lilik Hendrajaya,1990. Geolistrik Tahanan Jenis, Laboratorium Fisika BUmi. Jurusan Fisika, Fakultas Matematika dan IImu Pengetahuan Alam Institut Teknologi Bandung

Palacky, G., 1988. 3. Resistivity Characteristics of Geologic Targets, in: Electromagnetic Methods in Applied Geophysics, Investigations in Geophysics. Society of Exploration Geophysicists, pp. 52-129.

Reynolds, J. M. 1997. An Introduction to Aplied and Environmental Geophysicsi. John Wiley and Sons Ltd. Baffins, Chichester, West Susex PO19 IUD. England 
Resink, T., 1968. Belahan or a Mith Dispalled. Cornelll University Press.

Santosa, S., Suwarti, T., 1992. Peta Geologi Lembar Malang, Skala 1:100.000. Pusat Penelitian dan Pengembangan Geologi.

Sidomulyo $H, 2013$. Mengenal situs purbakala di gunung penanggungan. Universitas Surabaya (UBAYA).

Van Padang, N., 1951. Catalogue of volcanic activity and solfatara fi elds.

W. M. Telford, L. P. Geldart, R. E. Sheriff. 1990. Applied Geophysics. Cambridge University: Press New York. 